\section{International Scientific Journal Theoretical \& Applied Science}

p-ISSN: 2308-4944 (print) e-ISSN: 2409-0085 (online)

Year: 2017 Issue: $07 \quad$ Volume: 51
Yulduz Boyuk Aqa Ramazanova $\mathrm{PhD}$ in Chemistry, Assistant professor, Leading Scientific Researcher, Institute of Chemistry of Additives, Azerbaijan National Academy of Sciences, Azerbaijan pishnamazzadeh@mail.ru

SECTION 9. Chemistry and chemical technology.

\title{
SYNTHESIS OF S-CINNAMYL-CONTAINING XANTHATES AND ANALYSIS OF THEIR THERMAL AND LUBRICATING PROPERTIES
}

Abstract: The paper presents the results of studies on the preparation of organic compounds containing simultaneously cinnamyl and xanthogenic fragments in the structures, investigating their antiwear, extreme pressure, protective, and thermoanalytical properties that determine the stability of organic compounds offered as additives against temperature effects. High lubricating and protective properties of the composition consisting of 95\% of vaseline oil, 3\% cinnamylethylxanthate and 2\% ДФ-11 additive were defined.

Key words: styrene, xanthate, additive, lubricant composition, thermal stability.

Language: Russian

Citation: Ramazanova YB (2017) SYNTHESIS OF S-CINNAMYL-CONTAINING XANTHATES AND ANALYSIS OF THEIR THERMAL AND LUBRICATING PROPERTIES. ISJ Theoretical \& Applied Science, 07 (51): 28-33.

Soi: http://s-o-i.org/1.1/TAS-07-51-6 Doi: crossef https://dx.doi.org/10.15863/TAS.2017.07.51.6

\section{УДК 547.496+621.892.85}

\section{СИНТЕЗ S-ЦИННАМИЛСОДЕРЖАЩИХ КСАНТОГЕНАТОВ И ИСЛЕДОВАНИЕ ИХ ТЕРМИЧЕСКИХ И СМАЗЫВАЮЩИХ СВОЙСТВ}

Аннотация: В статье приводятся результаты исследований по получению органических соединений, содержащих в структурах одновременно ичинамиловый и ксантогеновый фрагменты. Исследованны их противоизносные, противозадирные, защиттные, а также термоаналитические свойства, определяющие устойчивость органических соединений, предлагаемых в качестве присадок против температурных воздействий. Установлены высокие смазывающие и защитные свойства композиции, состоящей из $95 \%$ вазелинового масла, 3\% ичиннамилэтилксантогената и 2\% присадки ДФ-11.

Ключевые слова: стирол, ксантогенат, присадка, , термическая стабильность, смазочная композиция.

\section{Введение}

Для надежной и длительной эксплуатации современных машин и механизмов в жестких режимах (при высоких скоростях скольжения и давлениях), необходимо использование трансмиссионных масел, отвечающих по комплексу показателей требуемым нормам . [1]

Наиболее важными эксплуатационными свойствами является их смазывающая способность. Трансмиссионные масла должны защищать трущиеся поверхности и узлы от износа, заедания и питтинговой коррозии, обладая достаточно высокой антиокислительной стабильностью, иметь хорошие вязкостнотемпературные свойства $[1,2]$.
Для легирования трансмиссионных масел длительное время использовались соединения, содержащие в своих структурах гетероатомы (S, $\mathrm{N}, \mathrm{P}, \mathrm{O})$ и различные функциональные группы. $\mathrm{C}$ развитием техники значительные изменения произошли в конструкции узлов трения промышленного оборудования, что в свою очередь вызвало необходимость разработки новых смазочных композиций с использованием ультратонких порошков $\mathrm{MoS}_{2}$, ПТФЭ, ПЭ и др. материалов, выполняющих роль модификаторов трения [3-5].

Эти композиции работоспособны в режиме граничной смазки, обеспечивают плавное 
скольжение трущихся узлов и значительное снижение коэффициента трения.

Разработаны также композиции, содержащие в составе серосодержащие соединения и производные фуллеренов [6].

Однако следует отметить, что широкое применение подобных композиций сдерживается из-за трудности изготовления ультратонких порошков и равномерного распределения их в масле.

Поэтому, несмотря на имеющиеся в этой области многочисленные исследования, предпочтение отдают маслорастворимым органическим соединениям, содержащим в структурах различные функциональные группы и гетероатомы [7].

К соединениям, нашедшим широкое применение в качестве противоизносных и противозадирных присадок, относятся ксантогенаты, синтез которых основан, в основном, на реакциях ксантогенатов щелочных металлов с галогенсодержащими соединениями. Однако практикой установлено, что применением отдельных видов присадок невозможно обеспечить получение высококачественных смазочных масел удовлетворяющих требованиям современных двигателей, поэтому промышленностью выпускаются масла с композициями присадок.

С целью получения высокоэффективных присадок к смазочным маслам, на основе циннамилхлорида и алкилксантогенатов калия синтезированы новые циннамилксантогенаты, с последующим исследованием их противозадирных, противоизносных и защитных свойств.

\section{Экспериментальная часть}

Синтез исходного циннамилхлорида производили взаимодействием стирола с параформом (формалином) в присутствии концентрированной соляной кислоты и серы по схеме:<smiles>C=Cc1ccccc1</smiles>

В реакционную колбу, снабженную мешалкой, термометром и обратным холодильником, загружали 104г (1 моль) стирола, 30г (1 моль) параформа, несколько крупинок гидрохинона, 1г серы и 375 мл концентрированной соляной кислоты ( $=1.18$

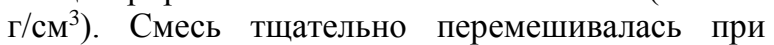
температуре $75^{\circ} \mathrm{C}$ в течение 5 часов.

Гидрохинон использовали для предотвращения гомополимеризации стирола, а серу в качестве катализатора. Аналогично реакцию проводили также с формалином.

По завершении реакции органический слой экстрагировали бензолом, промывали несколько раз дистиллированной водой, сушили над сульфатом натрия. Растворитель отгоняли воздушным насосом, а остаток - в вакууме (при 0.4 мм рт.ст).

Выход циннамилхлорида 85.2 г $(82.5 \%$ от теор.)

$$
n_{D}^{20}=1.5783 ; \quad d_{4}^{20}=1.0958
$$

Синтез целевых соединений проводили при эквимолярном соотношении циннамилхлорида и алкилксантогенатов калия в среде изопропанола при температуре $60^{\circ} \mathrm{C}$ и продолжительности реакции в течение 4-5 часов по схеме:<smiles>O=[Se](=S)C/C=C/c1ccccc1Cl</smiles>

где $\mathrm{R}=\mathrm{C}_{2} \mathrm{H}_{5}(\mathrm{I}), \mathrm{CH}\left(\mathrm{CH}_{3}\right)_{2}(\mathrm{II}), \mathrm{C}_{4} \mathrm{H}_{9}$ (III).

Циннамилксантогенаты представляют собой вязкие вещества растворимые в маслах.

Характеристика полученных циннамилксантогенатов приводится в табл. 1 . 
Физико-химические свойства синтезированных циннамилксантогенатов.

Таблица 1

\begin{tabular}{|c|c|c|c|c|c|c|}
\hline \multirow[b]{2}{*}{ Соединение } & \multirow{2}{*}{$\begin{array}{c}\text { Выход, } \\
\%\end{array}$} & \multirow{2}{*}{$\begin{array}{c}\mathrm{T}_{\text {кип. }}{ }^{0} \mathrm{C} / \\
\text { (мМ рт.ст.) }\end{array}$} & \multirow[b]{2}{*}{$n_{D}^{20}$} & \multirow[b]{2}{*}{$d_{4}^{20}$} & \multicolumn{2}{|c|}{$\mathrm{MR}_{\text {д }}$} \\
\hline & & & & & Найд. & Выч. \\
\hline$\underset{\|}{\mathrm{C}_{2} \mathrm{H}_{5} \mathrm{OCSCH}} \mathrm{CH}_{2} \mathrm{CH}=\mathrm{CHC}_{6} \mathrm{H}_{5}$ & 84 & $126-127 / 0.4$ & 1.6184 & 1.1311 & 73,39 & 71,77 \\
\hline $\begin{array}{c}\mathrm{i}-\mathrm{C}_{3} \mathrm{H}_{7} \mathrm{OCSCH}_{2} \mathrm{CH}=\mathrm{CHC}_{6} \mathrm{H}_{5} \\
\mathrm{~S}\end{array}$ & 82 & $120-125 / 0.4$ & 1.6070 & 1.1232 & 77,47 & 76,39 \\
\hline $\begin{array}{c}\mathrm{C}_{4} \mathrm{H}_{9} \mathrm{OCSCH}_{2} \mathrm{CH}=\mathrm{CHC}_{6} \mathrm{H}_{5} \\
\mathrm{~S}\end{array}$ & 80 & $130-131 / 0.4$ & 1.6310 & 1.1351 & 83,43 & 81,01 \\
\hline
\end{tabular}

Структуры соединений I-III были установлены методами ИК и ПМР-спектроскопии.

ИК-спектры сняты на спектрометре Spekord75 в области 400-4000 $\mathrm{cm}^{-1}$. ПМР-спектры сняты на спектрометре Varion T-60, данные ПМР-спектра соед. II: 1.4 д $\left(6 \mathrm{H}, \mathrm{C}\left(\mathrm{CH}_{3}\right)_{2}, 3.81\right.$ д $\left(2 \mathrm{H}, \mathrm{C}=\mathrm{CH}_{2}-\mathrm{S}\right)$, 5.55c. $(1 \mathrm{H}, \mathrm{C}-\mathrm{C}-\mathrm{CH}) ; 6.05 \mathrm{~T}(1 \mathrm{H}, \mathrm{C}=\mathrm{CH}-\mathrm{C}) ; 6.3$ д $(1 \mathrm{H}$, $\mathrm{A}=\mathrm{CH}=\mathrm{C}) ; 6.95 \mathrm{M}(5 \mathrm{H}, \mathrm{C}-\mathrm{H})$.

Исследования смазывающих свойств синтезированных соединений проводились на четырехшариковой машине трения (ЧМТ-1). Противозадирные свойства оценивались по ГОСТ 9490-75 по индексу задира $\left(И_{3}\right)$, по нагрузке сварки шаров $\left(\mathrm{P}_{\mathrm{c}}\right)$, по нагрузке перехода $\mathrm{\kappa}$ заеданию $\left(\mathrm{P}_{\kappa},\right)$. Противоизносные свойства масел оценивались по величине диаметре износа (Ди). Противоизносные свойства масел исследовались также на ЧМТ-1 при постоянных осевых нагрузках $137 \mathrm{H}$, скорости вращения верхнего шара 1420 об/мин, длительность испытания 1 час. Оценку производили по величине диаметра износа (Ди).

Термические свойства соединений I-III исследовались в динамическом режиме на дериватографе типа «ОД-102Т» системы Паулик, Эрдеи (Венгрия). $\mathrm{Al}_{2} \mathrm{O}_{3}$.

Скорость нагрева образца $5^{0} \mathrm{C} /$ мин., эталон -

Навеска испытуемого образца 0.1 г.

Для выявления поведения указанных соединений по отношению к металлу проводились также сравнительные испытания в присутствии порошка железа при соотношении 1:2 масс и 1:1 в случае электролитической чистой меди таб.4. [8, $9,10]$.

Температура начала интервала технических превращений соответствовала $5 \%$ потери массы образца от исходной навески, а температура конца указанного интервала определялась в точке выхода ДТА-, ТГ- и ДТГ- кривых на базисную линию.

Термоокислительная стабильность композиций определялась на приборе ДК-2НАМИ.

\section{Обсуждение результатов}

Используемый при синтезе циннамилксантогенатов циннамилхлорид, ранее синтезирован авторами [6], однако выход его не превышал 60-63\%. Как показали исследования, выход циннамилхлорида, возможно увеличить до $85 \%$, применением гидрохинона (как реагента, предотвращающего полимерзацию стирола).

На основании опубликованных, а также собственных работ, предложен механизм получения циннамилхлорида.

Выявлено, что реакция циннамилхлорида с ксантогенатами щелочных металлов легко протекает в изопропиловом спирте при температуре $60^{\circ} \mathrm{C}$ в течение 5 часов.

Исследование защитных свойств соединений проводились в вазелиновом масле.

Результаты исследований приводятся в таблицах 2 и 3.

$$
\begin{aligned}
& \mathrm{C}_{6} \mathrm{H}_{5} \mathrm{CH}=\mathrm{CH}_{2}+\stackrel{+}{\mathrm{C}} \mathrm{H}_{2} \mathrm{OH} \rightleftarrows \mathrm{C}_{6} \mathrm{H}_{5} \stackrel{+}{\mathrm{C}} \mathrm{H}-\mathrm{CH}_{2}-\mathrm{CH}_{2} \mathrm{OH} \\
& \mathrm{C}_{6} \mathrm{H}_{5} \stackrel{+}{\mathrm{C}} \mathrm{H}-\mathrm{CH}_{2}-\mathrm{CH}_{2} \mathrm{OH} \underset{+\stackrel{+}{+}}{\stackrel{+}{\rightleftarrows}} \mathrm{C}_{6} \mathrm{H}_{5} \mathrm{CH}=\mathrm{CH}-\mathrm{CH}_{2} \mathrm{OH} \\
& \mathrm{C}_{6} \mathrm{H}_{5} \mathrm{CH}=\mathrm{CH}-\mathrm{CH}_{2} \mathrm{OH}+\mathrm{HCl} \rightleftarrows \mathrm{C}_{6} \mathrm{H}_{5} \mathrm{CH}=\mathrm{CH}-\mathrm{CH}_{2} \mathrm{Cl}+\mathrm{H}_{2} \mathrm{O}
\end{aligned}
$$




\begin{tabular}{|c|c|c|c|c|c|c|}
\hline Impact Factor: & $\begin{array}{l}\text { ISRA (India) } \\
\text { ISI (Dubai, UAE } \\
\text { GIF (Australia) } \\
\text { JIF }\end{array}$ & $\begin{array}{l}=1.344 \\
=0.829 \\
=0.564 \\
=1.500\end{array}$ & $\begin{array}{l}\text { SIS (USA) } \\
\text { PИНЦ (Russia) } \\
\text { ESJI (KZ) } \\
\text { SJIF (Morocco) }\end{array}$ & $\begin{array}{l}=0.912 \\
=0.234 \\
=3.860 \\
=\mathbf{2 . 0 3 1}\end{array}$ & $\begin{array}{l}\text { ICV (Poland) } \\
\text { PIF (India) } \\
\text { IBI (India) }\end{array}$ & $\begin{array}{l}=6.630 \\
=1.940 \\
=4.260\end{array}$ \\
\hline
\end{tabular}

Таблица 2

Результаты исследований смазывающих свойств соединений I-III на ЧМТ-1.

\begin{tabular}{|c|c|c|c|c|c|}
\hline \multirow{2}{*}{ Соединение } & \multirow{2}{*}{\begin{tabular}{c} 
Концентраци \\
я соединений \\
\cline { 3 - 5 }
\end{tabular}} & \multicolumn{2}{|c|}{ Противозадирные характеристики } & \multirow{2}{*}{ Д, мм } \\
\cline { 3 - 5 } & $\mathrm{P}_{\text {к }}, \mathrm{H}$ & $\mathrm{P}_{\mathrm{c}}, \mathrm{H}$ & $\mathrm{И}_{3}, \mathrm{H}$ & \\
\hline Вазелиное масло & - & 549 & 1382 & 206 & 0.74 \\
\hline I & 4.55 & 1235 & 2930 & 534 & 0.78 \\
\hline II & 5.04 & 1266 & 2764 & 529 & 0.76 \\
\hline III & 5.32 & 1098 & 2450 & 490 & 0.73 \\
\hline
\end{tabular}

Как видно из представленных данных в табл. 2, исследованные циннамилксантогенаты обладают высокими противозадирными свойствами, о чем свидетельствуют значения $\mathrm{P}_{\text {к }}$ и $И_{3}$, значения Ди указывают на то, что противоизносными свойствами циннамилксантогенаты практически не обладают.
В связи с чем была составлена композиция с промышленной противоизносной присадкой ДФ11, смазывающие, антикоррозионные, антиржавейные свойства и термоокислительная стабильность которой представлены в табл. 3.

Таблица 3

Результаты испытаний циннамилэтилксантогената как в чистом виде, так и в составе композиции в сравнении с контрольным маслом.

\begin{tabular}{|c|c|c|c|}
\hline Показатели & $\begin{array}{l}\text { Вазелиновое } \\
\text { масло }\end{array}$ & $\begin{array}{c}\text { Вазелиновое } \\
\text { масло } \\
+3 \% \text { соед.I }\end{array}$ & $\begin{array}{l}\text { Вазелиновое } \\
\text { масло } \\
+3 \% \text { соед.I } \\
+2 \% Д Ф-11 \\
\end{array}$ \\
\hline $\begin{array}{l}\text { Смазывающие свойства: } \\
\text { - индекс задира, И, }, \mathrm{H} \\
\text { - критическая нагрузка, } \mathrm{P}_{\kappa}, \mathrm{H} \\
\text { - нагрузка сваривания, } \mathrm{P}_{\mathrm{c}}, \mathrm{H} \\
\text { - диаметр износа, Д Ди }\end{array}$ & $\begin{array}{c}255 \\
560 \\
1120 \\
0,74\end{array}$ & $\begin{array}{c}343 \\
980 \\
1381 \\
0,78\end{array}$ & $\begin{array}{c}372 \\
1234 \\
2450 \\
0,52\end{array}$ \\
\hline $\begin{array}{l}\text { Коррозия меди (по методу ASTM D-130), баллы: } \\
- \text { при } 120^{\circ} \mathrm{C}, 3 \text { час } \\
\text { - при } 140^{\circ} \mathrm{C}, 3 \text { час } \\
\text { - при } 150^{\circ} \mathrm{C}, 3 \text { час }\end{array}$ & $\begin{array}{l}3 \mathrm{в} \\
3 \mathrm{~B} \\
3 \mathrm{~B}\end{array}$ & $\begin{array}{l}1 \mathrm{a} \\
1 \mathrm{~B} \\
-\end{array}$ & $\begin{array}{l}1 \mathrm{a} \\
1 \mathrm{~B} \\
-\end{array}$ \\
\hline $\begin{array}{l}\text { Коррозия (защитные свойства } \\
\text { по ГОСТ 9.054.75), \% } \\
\text { - в камере Г-4 (20 час) } \\
\text { - в морской воде, } 20 \text { час } \\
\text { - в морской воде, } 40 \text { час }\end{array}$ & $\begin{array}{c}70 \\
90 \\
100\end{array}$ & $\begin{array}{c}94 \\
90 \\
6\end{array}$ & $\begin{array}{c}92 \\
63 \\
4\end{array}$ \\
\hline $\begin{array}{l}\left.\text { Термоокислительная стабильность (при } 150^{\circ} \mathrm{C}\right) \text { : } \\
\text { - осадок в окисленном масле }\end{array}$ & 0.10 & 0.07 & 0.11 \\
\hline
\end{tabular}

Как видно из результатов сравнительных исследований (табл.3), при сочетании в композиции соед. I и присадки ДФ-11 улучшаются смазывающие и защитные свойства вазелинового масла.
В табл. 4 приводятся результаты термических исследований соед. I и II без металла и с металлом ( $\mathrm{Fe}$ или $\mathrm{Cu})$. 


\begin{tabular}{l|lrl|l|ll} 
& ISRA (India) & $=\mathbf{1 . 3 4 4}$ & SIS (USA) & $=\mathbf{0 . 9 1 2}$ & ICV (Poland) & $=\mathbf{6 . 6 3 0}$ \\
Impact Factor: & ISI (Dubai, UAE) $=\mathbf{0 . 8 2 9}$ & PUHL (Russia) $=\mathbf{0 . 2 3 4}$ & PIF (India) & $=\mathbf{1 . 9 4 0}$ \\
& GIF (Australia) & $\mathbf{0 . 5 6 4}$ & ESJI (KZ) & $=3.860$ & IBI (India) & $=\mathbf{4 . 2 6 0}$ \\
& JIF & $=\mathbf{1 . 5 0 0}$ & SJIF (Morocco) & $=\mathbf{2 . 0 3 1}$ & & \\
\hline
\end{tabular}

Термоаналитические данные исследований.

Таблица 4

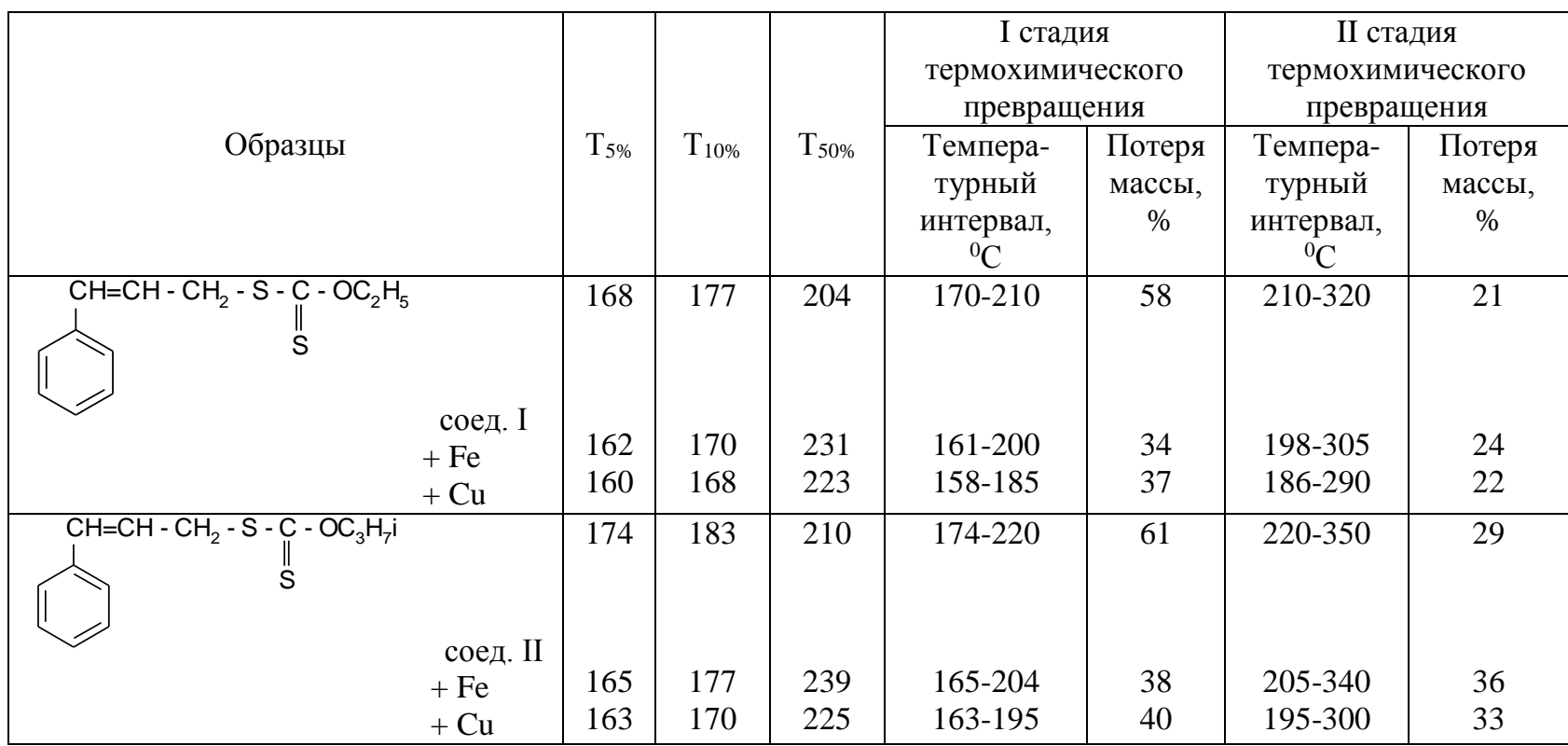

Установлено, что термохимические превращения испытанных соединений проходят в две стадии. Потеря массы соединения I в первой стадии (в температурном интервале $170-210^{\circ} \mathrm{C}$ ) составляет $58 \%$, во второй стадии (в температурном интервале $\left.210-320^{\circ} \mathrm{C}\right) \quad 21 \%$. В присутствии порошков металлов в обеих стадиях наблюдается уменьшение потери масс. Примерно такие же закономерности наблюдаются и в случае термических превращений соединения II. Очевидно, такое поведение этих соединений можно объяснить химическим взаимодействием их с металлами (при повышенных температурах), что является важным фактором при подборе присадок к трансмиссионным и моторно-промышленным маслам.

За счет химической модификации металла, поверхностям трущихся узлов обеспечивается эффективная защита от преждевременного износа и коррозии.
Таким образом, выявлена возможность использования синтезированных соединений в пакетах с известными промышленными присадками. При этом исключается явление антагонизма между ними и обеспечиваются достаточно высокие эксплуатационные свойства.

\section{Выводы}

Синтезированы и исследованы в качестве присадок циннамилксантогенаты. Разработана на их основе композиция присадок с противоизносной промышленной присадкой

ДФ-11, обладающая высокой смазывающей эффективностью. Установлена устойчивость синтезированных соединений против температурного воздействия.

\section{References:}

1. (1999) Topliva, smazochnye materialy, tekhnicheskie zhidkosti. Spravochnik pod red. V.M.Shkol'nikova. M.: Izd. Tsentr «Tekhinform». 1999. p. 185-200.

2. Vipper AB, Vilenkin AV, Gaysner DA (1981) Zarubezhnye masla i prisadki. M:. Izd. «Khimiya». 1981. p. 83.
3. Kholodov BP, Katashov YN, Kozlovtsev AP, et al. (1990) «Dispersii disul'fida molibdena V maslakh»//Khimiya i tekhnologiya topliv $\mathrm{i}$ masel. 1990. № 7. p. 12-13

4. Evdokimov YA, Kornev VI, Bulgarevich SB, et al. (2002) «Kompozitsiya prisadok $\mathrm{k}$ smazochnomu maslu dlya 


\begin{tabular}{l|lrl|l|ll} 
& ISRA (India) & $=\mathbf{1 . 3 4 4}$ & SIS (USA) & $=\mathbf{0 . 9 1 2}$ & ICV (Poland) & $=\mathbf{6 . 6 3 0}$ \\
Impact Factor: & ISI (Dubai, UAE) $=\mathbf{0 . 8 2 9}$ & PUHL (Russia) $=\mathbf{0 . 2 3 4}$ & PIF (India) & $=\mathbf{1 . 9 4 0}$ \\
& GIF (Australia) & $\mathbf{0 . 5 6 4}$ & ESJI (KZ) & $=3.860$ & IBI (India) & $=\mathbf{4 . 2 6 0}$ \\
& JIF & $=\mathbf{1 . 5 0 0}$ & SJIF (Morocco) & $=\mathbf{2 . 0 3 1}$ & & \\
\hline
\end{tabular}

tyazhelonagruzhennykh uzlov treniya» // Khimiya i tekhnologiya topliv i masel. 2002. № 2. p. 23-24.

5. Grigor'eva NI, Gavrilova IA, Tyurina TV, et al. (2003) «Kompozitsiya prisadok k smazochnomu maslu dlya tyazhelonagruzhennykh uzlov treniya promyshlennogo oborudovaniya»//Khimiya i tekhnologiya topliv i masel. 2003. № 3. p. 2935 .

6. (2010) Pat. RF 2382816 (opubl. 2010)

7. Kaizhonq Fan, Zing Li, Haibinq Mo (2008) //Tribol. Int. 2008. 41. № 12. C. 1226.

8. 8.Berg L. Vvedenie $\mathrm{v}$ termografiyu. M.Nauka.1969. p. 365.
9. Akchurina TK, Safarova MR, Kulieva MA (2006) ///Termicheskaya stabil'nost' i reaktsionnaya sposobnost' $\mathrm{k}$ metallam nekotorykh atsetoksi-i vinilkarbolovykh efirov ksantogenovoy i ditiokarbaminovoy i ditiofosfornoy kislot» Neftepererabotka i neftekhimiya. 2006. № 11. p. 21-25.

10. Akchurina TK, Kulieva MA, Ramazanova YB, et al. (2007) «Termoanaliticheskie issledovaniya nekotorykh zameshchennykh oksimetilovykh i oksikarbonilmetilovoy kislot». // Azerbaydzhanskiy khimicheskiy zhurnal. 2007. № 4. p. 64-68. 